\title{
Repetibilidade e número de colheitas para seleção de clones de cana-de-açúcar
}

\author{
Adésio Ferreira ${ }^{(1)}$, Márcio Henrique Pereira Barbosa ${ }^{(1)}$, Cosme Damião Cruz ${ }^{(1)}$, Hermann Paulo Hoffmann ${ }^{(2)}$, \\ Marcos Antonio Sanches Vieira ${ }^{(2)}$, Antonio Ismael Bassinello(2) e Marcia Flores da Silva ${ }^{(1)}$
}

(1)Universidade Federal de Viçosa, CEP 36570-000 Viçosa, MG. E-mail: adesio@vicosa.ufv.br, barbosa@ufv.br, cdcruz@ufv.br, mfloress@vicosa.ufv.br (2)Universidade Federal de São Carlos, Campus de Araras, Via Anhanguera, Km 174, Caixa Postal 153, CEP 13600-970 Araras SP. E-mail: hermann.hoffmann@dbv.cca.ufscar.br, marcos@dbv.cca.ufscar.br, bassinello@dbv.cca.ufscar.br

\begin{abstract}
Resumo - Os objetivos deste trabalho foram estabelecer estimativas dos coeficientes de repetibilidade (r) e determinar a previsibilidade $\left(\mathrm{R}^{2}\right)$ e o número de medições necessárias das características toneladas de colmos por hectare, toneladas de sacarose no caldo da cana por hectare e teor de sacarose dos colmos, pol porcento cana, em genótipos de cana-de-açúcar. O delineamento experimental utilizado foi o de blocos casualizados, com três repetições em quatro experimentos e quatro repetições nos demais experimentos. As estimativas de repetibilidade foram obtidas pelos métodos estatísticos da análise de variância, componentes principais com base na matriz de correlações e análise estrutural (correlação, $\mathrm{r}$ - médio). As estimativas dos coeficientes de repetibilidade revelaram valores muito semelhantes. A repetibilidade média geral nas três características foi superior a 0,60 , demonstrando regularidade do desempenho dos genótipos nas várias medições (cortes) e confiabilidade na discriminação genotípica superior a 87\%. Verificou-se, nas três características, a necessidade do emprego de no mínimo três cortes, para que a seleção possa ser praticada com previsibilidade do valor real do genótipo acima de $80 \%$.
\end{abstract}

Termos para indexação: Saccharum spp., clones, análise de variância, componentes principais, análise estrutural.

\section{Repeatability and harvest numbers in selecting sugarcane clones}

\begin{abstract}
This work aimed at the establishment of the repeatability coefficients (r), determination of the predictability degree $\left(R^{2}\right)$ and the needed measurement numbers for tons of cane per hectare, percentage of pol (sucrose) in the juice of cane and tons of pol in the juice of cane per hectare in sugarcane genotypes. A randomized block experimental design, with three replicates in four experiments and four replicates in the other experiments was used. The repeatability estimates were obtained by the statistical methods: anova; main components based on correlation matrix; and structural analysis (correlation, average r). The estimates of the repeatability coefficients showed values with very similar magnitude. The general average repeatability for those three traits was above 0.60 , therefore showing regularity in the genotype performance at several measurements (cuts) and reliability in the genotype discrimination that was higher than $87 \%$. The results showed that for those three traits there is a need for the use of, at least, three cuts so that the selection can be accomplished with predictability of a real value above $80 \%$ for the genotype.
\end{abstract}

Index terms: Saccharum spp., clones, variance analysis, main components, structural analysis.

\section{Introdução}

A cana-de-açúcar é um produto de destaque no cenário econômico e social brasileiro, e o seu bom desempenho está atrelado aos programas de melhoramento genético (Rosse et al., 2002).

De acordo com Barbosa et al. (2000), nas últimas três décadas, foi marcante a contribuição do melhoramento genético no desenvolvimento do setor canavieiro do Brasil, com ganhos acentuados em produtividade e qualidade.
Nesse período, houve mais de 30\% de aumento na média em produtividade da cana-de-açúcar e da recuperação de quilogramas de açúcar por tonelada de cana moída.

A eficácia dos programas de melhoramento da canade-açúcar depende principalmente da repetibilidade espacial e temporal dos caracteres sob seleção (Cuenya \& Mariotti, 1993). A constituição genética dos clones selecionados é fixada pela propagação vegetativa. 
Portanto, em todas as fases do programa de melhoramento, a avaliação segura da superioridade genotípica é fundamental e, conseqüentemente, a repetibilidade dos caracteres ao longo dos anos torna-se informação indispensável para o melhorista (Falconer \& Mackay, 1966). Miller \& James (1975) e Mariotti (1973) citam alguns trabalhos, com cana-de-açúcar, que se fundamentaram em informações da repetibilidade obtidas por diferentes técnicas biométricas, objetivando elevar o índice de eficiência dos métodos de seleção.

O coeficiente de repetibilidade da característica possibilita estabelecer o número de observações fenotípicas que devem ser realizadas em cada indivíduo para que a discriminação, ou seleção, fenotípica entre genótipos seja eficiente, ou seja, consuma menos tempo e tenha menor custo de mão-de-obra (Ferreira et al., 1999; Cruz \& Regazzi, 2001). Adicionalmente, a repetibilidade fornece o valor máximo que a herdabilidade no sentido amplo pode atingir, pois expressa a proporção da variância fenotípica que é atribuída às diferenças genéticas confundidas com os efeitos permanentes que atuam na cultivar. Assim, esses parâmetros constituem instrumentos úteis para orientar os trabalhos de melhoramento (Botrel et al., 2000).

Há diversos métodos descritos para estimativa do coeficiente de repetibilidade. Cruz \& Regazzi (2001) apresentaram a obtenção das estimativas de repetibilidade pelos métodos da análise de variância; componentes principais, demonstrado por Abeywardena (1972), é o mais adequado para estimar o coeficiente de repetibilidade quando, ao longo das avaliações, os genótipos apresentam comportamento cíclico, em relação ao caráter estudado; análise estrutural, método proposto por Mansour et al. (1981), apresenta apenas diferenças conceituais em relação ao método dos componentes principais e, segundo seus autores, é mais adequado quando as variâncias nas diversas medições não são homogêneas.

O objetivo deste trabalho foi obter estimativas dos coeficientes de repetibilidade (r), determinação ou grau de previsibilidade $\left(\mathrm{R}^{2}\right)$ das características toneladas de colmos por hectare, porcentagem de sacarose e toneladas de sacarose por hectare em clones de cana-de-açúcar, e determinar o número de medições necessárias capaz de proporcionar níveis de certeza da predição do valor real dos indivíduos para cada caráter.

\section{Material e Métodos}

Avaliaram-se os dados de produtividade de colmos (toneladas de colmos por hectare - TCH), teor de sacarose dos colmos (pol porcento cana - PCC) e tonelada de pol (sacarose) no caldo da cana por hectare (TPH) provenientes de 16 experimentos instalados em regiões produtoras representativas do Brasil, compreendendo os estados de Minas Gerais, São Paulo e Goiás.

As colheitas foram realizadas em diferentes épocas (Tabela 1). Foram realizadas várias medições ao longo do tempo, correspondentes a sete cortes no experimento 4 , seis cortes no experimento 13 e cinco cortes nos demais experimentos. $\mathrm{O}$ delineamento experimental usado foi o de blocos casualizados, com três repetições nos experimentos 1, 4, 14 e 16 e com quatro repetições nos demais experimentos. A unidade experimental foi constituída por cinco fileiras de 8 ou $10 \mathrm{~m}$ de comprimento, espaçadas em 1,40 m. O número de genótipos nos experimentos variou de 12 a 35 .

Esses experimentos corresponderam à última fase de avaliação de clones do programa de melhoramento genético da cana-de-açúcar da Rede Interuniversitária para Desenvolvimento do Setor Sucroalcooleiro RIDESA no centro-sul do Brasil.

Com base na média das repetições de cada corte, obtiveram-se as estimativas do coeficiente de repetibilidade $(\hat{\rho})$ e o coeficiente de determinação ou grau de previsibilidade de cada caráter $\left(\mathrm{R}^{2}\right)$.

Foram realizadas análises de variâncias em esquema fatorial com dois fatores de variação, correspondentes a genótipos e cortes, para as três características em todos os experimentos com a finalidade de estimar a

Tabela 1. Relação dos locais, números de cortes, épocas dos cortes e número de genótipos em cada experimento.

\begin{tabular}{clccc}
\hline $\begin{array}{c}\text { Número do } \\
\text { experimento }\end{array}$ & \multicolumn{1}{c}{ Município } & $\begin{array}{c}\text { Épocas de } \\
\text { cortes (anos) }\end{array}$ & $\begin{array}{c}\text { Número } \\
\text { de cortes }\end{array}$ & $\begin{array}{c}\text { Número de } \\
\text { genótipos }\end{array}$ \\
\hline 1 & Guariba, SP & 1993 a 1997 & 5 & 18 \\
2 & Rio das Pedras, SP & 1992 a 1996 & 5 & 20 \\
3 & Pradópolis, SP & 1992 a 1996 & 5 & 20 \\
4 & Nova Europa, SP & 1993 a 1999 & 7 & 30 \\
5 & Pompéu, MG & 1992 a 1996 & 5 & 14 \\
6 & Pompéu, MG & 1992 a 1996 & 5 & 14 \\
7 & Urucânia, MG & 1991 a 1995 & 5 & 22 \\
8 & Urucânia, MG & 1991 a 1995 & 5 & 22 \\
9 & São João da Boa Vista, SP & 1992 a 1996 & 5 & 35 \\
10 & São Pedro dos Ferros, MG & 1991 a 1995 & 5 & 12 \\
11 & Pradópolis, SP & 1990 a 1994 & 5 & 15 \\
12 & Guairá, SP & 1994 a 1998 & 5 & 30 \\
13 & Goiatuba, GO & 1997 a 2002 & 6 & 20 \\
14 & Nova Europa, SP & 1996 a 2000 & 5 & 30 \\
15 & João Pinheiro, MG & 1996 a 2000 & 5 & 15 \\
16 & Monte Belo, MG & 1998 a 2002 & 5 & 15 \\
\hline
\end{tabular}


existência de variabilidade genética, a repetibilidade, os coeficientes de variação ambiental e a média do caráter.

Na estimação do coeficiente de repetibilidade, foram utilizados três métodos estatísticos: método da análise da variância com dois fatores de variação (cortes e genótipos) - ANOVA; método dos componentes principais com base na matriz de correlações - CP; método da análise estrutural (correlação, $\mathrm{r}$ - médio) - AE.

No método de análise de variância, o modelo estatístico utilizado (Cruz \& Regazzi, 2001) foi o seguinte: $\mathrm{Y}_{\mathrm{ij}}=\mu+\mathrm{g}_{\mathrm{i}}+\mathrm{a}_{\mathrm{j}}+\varepsilon_{\mathrm{ij}}$, em que $\mathrm{Y}_{\mathrm{ij}}$ é a observação referente ao i-ésimo genótipo no j-ésimo corte; $\mu$ é a média geral; $g_{i}$ é o efeito aleatório do i-ésimo genótipo confundido com os efeitos permanentes do ambiente $(i=1,2,3, \ldots, p) ; a_{j}$ é o efeito fixo do j-ésimo corte $(\mathrm{j}=1,2, \ldots, \eta)$; $\varepsilon_{\mathrm{ij}}$ é o erro experimental associado à observação $Y_{i j}$.

Por meio da análise de variância para o modelo utilizado, foram obtidos os quadrados médios $(\mathrm{QM})$ e as esperanças dos quadrados médios [E(QM)], para genótipos e resíduo, respectivamente, dados por $\left(\sigma^{2}+\eta \sigma_{\mathrm{g}}{ }^{2}\right)$ e $\left(\sigma^{2}\right)$. Assim, segundo Cruz \& Regazzi (2001), o coeficiente de repetibilidade é dado por: $r=\frac{\operatorname{Côv}\left(Y_{i j}, Y_{i j}\right)}{\sqrt{\hat{V}\left(Y_{i j}\right) \hat{V}\left(Y_{i j}\right)}}=\frac{\hat{\sigma}_{g}^{2}}{\hat{\sigma}_{f}^{2}}=\frac{\hat{\sigma}_{g}^{2}}{\hat{\sigma}_{g}^{2}+\hat{\sigma}^{2}}$,

em que r é o coeficiente de repetibilidade; $\hat{\sigma}_{\mathrm{g}}^{2}$ é a variância atribuída aos efeitos confundidos de genótipo e ambiente permanente; $\hat{\sigma}^{2}$ é a variância residual.

O método dos componentes principais com base na matriz de correlações (R), descrito por Abeywardena (1972), consiste em obter uma matriz de correlações (R) entre os genótipos em cada par de medições $(\rho)$ (ou período de avaliações):

$R=\left[\begin{array}{cccc}1 & \rho & \ldots & \rho \\ \rho & 1 & \ldots & \rho \\ \ldots & \ldots & \ldots & \ldots \\ \rho & \rho & \ldots & 1\end{array}\right]_{\eta}$

O estimador do coeficiente de repetibilidade (r), segundo Cruz \& Regazzi (2001), é obtido com o ajuste proposto por Rutledge (1974) pela expressão:

$\mathrm{r}=\frac{\hat{\lambda}_{1}-1}{\eta-1}$, sendo $\hat{\lambda}_{1}$ o autovalor de $\mathrm{R}$ associado ao autovetor, cujos elementos têm sinal e magnitude semelhante.
O método da análise estrutural para obtenção do coeficiente de repetibilidade, proposto por Mansour et al. (1981), apresenta apenas diferenças conceituais em relação ao método dos componentes principais (Cruz \& Regazzi, 2001). Neste método, considera-se R a matriz paramétrica de correlações entre os genótipos em cada par de avaliação e $\hat{R}$ o seu estimador.

Um estimador do coeficiente de repetibilidade baseado na análise estrutural é dado por:

$\mathrm{r}=\frac{\alpha^{\prime} \hat{\mathrm{R}} \alpha-1}{\eta-1}$

em que $\alpha^{\prime}=[1 / \sqrt{\eta} \ldots 1 / \sqrt{\eta}]$ é o autovetor com elementos paramétricos associados ao maior autovalor de $\mathrm{R}$.

Como neste caso verifica-se que

$\alpha^{\prime} \hat{R} \alpha=1+\frac{2}{\eta} \sum_{j} \sum_{<j^{\prime}} r_{j ;}$,

conseqüentemente

$\mathrm{r}=\frac{2}{\eta(\eta-1)} \sum_{\mathrm{j}} \sum_{<\mathrm{j}^{\prime}} \mathrm{r}_{\mathrm{j} \mathrm{j}^{\prime}}$.

Assim, este estimador do coeficiente de repetibilidade é a média aritmética das correlações fenotípicas entre genótipos, considerando cada par de medições.

O coeficiente de determinação $\left(R^{2}\right)$ foi obtido pela expressão:

$\mathrm{R}^{2}=\eta \mathrm{r} /[1+\mathrm{r}(\eta-1)]$.

Na obtenção do número mínimo de medições $\left(\eta_{0}\right)$, que prediz o valor real do genótipo, utilizou-se a expressão: $\eta_{0}=\mathrm{R}^{2}(1-\mathrm{r}) /\left(1-\mathrm{R}^{2}\right) \mathrm{r}$.

Todas as análises estatísticas foram realizadas utilizando-se o programa computacional Genes (Cruz, 1997).

\section{Resultados e Discussão}

Em todos os experimentos, a existência de variabilidade genética foi detectada pelo teste $\mathrm{F}$ a $1 \%$ de probabilidade, nas três características avaliadas (Tabelas 2, 3 e 4). Isso indica possibilidade de identificação de clones promissores.

Os experimentos demonstraram boa precisão experimental, com pequenos valores de coeficientes de variação (CV). A característica TCH apresentou CV de $5,81 \%$ a $17,16 \%$ (Tabela 2). O CV para PCC foi de $2,58 \%$ a $6,18 \%$, evidenciando melhor precisão experimental na avaliação desta característica (Tabela 3). A precisão experimental detectada para a característi- 
ca TPH foi muito semelhante a TCH, exibindo valores de $6,83 \%$ a $17,60 \%$ (Tabela 4). Esses resultados corroboram os de Santos et al. (2004).

As estimativas dos coeficientes de repetibilidade obtidas pela informação de cortes realizados na cana-de-

Tabela 2. Médias dos ensaios, coeficientes de variação experimental, estimativas de coeficientes de determinação e de repetibilidade obtidos pelos métodos da análise de variância (ANOVA), método de componentes principais (CP) e método de análise estrutural (AE), da característica toneladas de colmos por hectare (TCH) de genótipos de cana-de-açúcar.

\begin{tabular}{|c|c|c|c|c|c|c|c|c|}
\hline \multirow[t]{2}{*}{ Experimento } & \multirow[t]{2}{*}{ Média $^{(1)}$} & \multirow{2}{*}{$\begin{array}{l}\mathrm{CV} \\
(\%)\end{array}$} & \multicolumn{2}{|c|}{ ANOVA } & \multicolumn{2}{|c|}{$\mathrm{CP}$} & \multicolumn{2}{|c|}{$\mathrm{AE}$} \\
\hline & & & $\mathrm{r}$ & $\mathrm{R}^{2}$ & $\mathrm{r}$ & $\mathrm{R}^{2}$ & $\mathrm{r}$ & $\mathrm{R}^{2}$ \\
\hline 1 & 103,73 & 10,40 & 0,82 & 95,84 & 0,83 & 96,15 & 0,83 & 96,06 \\
\hline 2 & 89,71 & 6,60 & 0,67 & 90,87 & 0,69 & 91,65 & 0,68 & 91,35 \\
\hline 3 & 89,92 & 8,48 & 0,68 & 91,41 & 0,70 & 92,05 & 0,69 & 91,73 \\
\hline 4 & 80,79 & 9,77 & 0,66 & 93,19 & 0,68 & 93,79 & 0,68 & 93,62 \\
\hline 5 & 78,35 & 10,94 & 0,66 & 90,56 & 0,68 & 91,25 & 0,65 & 90,31 \\
\hline 6 & 92,75 & 11,54 & 0,66 & 90,62 & 0,68 & 91,56 & 0,67 & 91,10 \\
\hline 7 & 76,43 & 10,82 & 0,68 & 91,55 & 0,72 & 92,77 & 0,72 & 92,68 \\
\hline 8 & 75,27 & 10,46 & 0,61 & 88,84 & 0,65 & 90,44 & 0,64 & 90,02 \\
\hline 9 & 90,68 & 17,16 & 0,42 & 78,37 & 0,54 & 85,48 & 0,42 & 78,32 \\
\hline 10 & 83,87 & 5,81 & 0,73 & 93,01 & 0,76 & 93,92 & 0,74 & 93,38 \\
\hline 11 & 94,08 & 6,63 & 0,82 & 95,86 & 0,84 & 96,32 & 0,84 & 96,30 \\
\hline 12 & 105,40 & 7,22 & 0,49 & 82,82 & 0,52 & 84,33 & 0,51 & 83,73 \\
\hline 13 & 105,04 & 7,84 & 0,60 & 89,92 & 0,61 & 90,28 & 0,60 & 89,97 \\
\hline 14 & 95,55 & 7,35 & 0,77 & 94,36 & 0,79 & 94,92 & 0,78 & 94,80 \\
\hline 15 & 102,82 & 9,40 & 0,70 & 92,20 & 0,73 & 92,97 & 0,71 & 92,52 \\
\hline 16 & 85,44 & 11,20 & 0,51 & 83,82 & 0,52 & 84,49 & 0,51 & 83,96 \\
\hline Média & - & - & 0,66 & 90,20 & 0,68 & 91,40 & 0,67 & 90,62 \\
\hline Desvio & - & - & 0,11 & 4,78 & 0,10 & 3,75 & 0,11 & 4,83 \\
\hline Máximo & - & - & 0,82 & 95,86 & 0,84 & 96,32 & 0,84 & 96,30 \\
\hline Mínimo & - & - & 0,42 & 78,37 & 0,52 & 84,33 & 0,42 & 78,32 \\
\hline
\end{tabular}

${ }^{(1)}$ Todas as médias diferem entre si a $1 \%$ de probabilidade pelo teste $\mathrm{F}$.

Tabela 3. Médias dos ensaios, coeficientes de variação experimental, estimativas de coeficientes de determinação e de repetibilidade, obtidos pelos métodos da análise de variância (ANOVA), método de componentes principais (CP) e método de análise estrutural (AE), da característica teor de sacarose dos colmos pol porcento cana (PCC) de genótipos de canade-açúcar.

\begin{tabular}{|c|c|c|c|c|c|c|c|c|}
\hline \multirow[t]{2}{*}{ Experimento } & \multirow[t]{2}{*}{ Média $^{(1)}$} & \multirow{2}{*}{$\begin{array}{l}\mathrm{CV} \\
(\%)\end{array}$} & \multicolumn{2}{|c|}{ ANOVA } & \multicolumn{2}{|c|}{$\mathrm{CP}$} & \multicolumn{2}{|c|}{$\mathrm{AE}$} \\
\hline & & & $\mathrm{r}$ & $\mathrm{R}^{2}$ & $\mathrm{r}$ & $\mathrm{R}^{2}$ & $\mathrm{r}$ & $\mathrm{R}^{2}$ \\
\hline 1 & 14,82 & 3,30 & 0,49 & 82,49 & 0,50 & 83,12 & 0,48 & 82,29 \\
\hline 2 & 14,44 & 3,58 & 0,79 & 95,03 & 0,80 & 95,35 & 0,80 & 95,31 \\
\hline 3 & 14,39 & 3,43 & 0,84 & 96,44 & 0,85 & 96,67 & 0,85 & 96,66 \\
\hline 4 & 16,09 & 2,93 & 0,61 & 91,70 & 0,62 & 92,05 & 0,62 & 91,94 \\
\hline 5 & 15,28 & 2,99 & 0,69 & 91,77 & 0,71 & 92,36 & 0,70 & 92,19 \\
\hline 6 & 14,96 & 2,58 & 0,77 & 94,24 & 0,77 & 94,45 & 0,77 & 94,41 \\
\hline 7 & 14,97 & 2,75 & 0,74 & 93,32 & 0,74 & 93,52 & 0,74 & 93,38 \\
\hline 8 & 15,24 & 3,11 & 0,59 & 87,63 & 0,59 & 87,72 & 0,58 & 87,29 \\
\hline 9 & 13,88 & 5,14 & 0,46 & 80,78 & 0,51 & 84,12 & 0,44 & 79,54 \\
\hline 10 & 14,19 & 3,16 & 0,40 & 76,94 & 0,47 & 81,79 & 0,37 & 74,49 \\
\hline 11 & 14,63 & 2,94 & 0,84 & 96,22 & 0,85 & 96,51 & 0,85 & 96,49 \\
\hline 12 & 12,51 & 6,18 & 0,37 & 74,71 & 0,41 & 77,64 & 0,38 & 75,75 \\
\hline 13 & 15,24 & 3,21 & 0,63 & 91,01 & 0,65 & 91,77 & 0,65 & 91,73 \\
\hline 14 & 15,11 & 3,36 & 0,58 & 87,17 & 0,59 & 87,76 & 0,58 & 87,39 \\
\hline 15 & 15,92 & 4,05 & 0,48 & 82,29 & 0,51 & 83,87 & 0,49 & 82,73 \\
\hline 16 & 13,08 & 4,76 & 0,62 & 89,04 & 0,63 & 89,59 & 0,56 & 86,25 \\
\hline Média & - & - & 0,62 & 88,17 & 0,64 & 89,27 & 0,62 & 87,99 \\
\hline Desvio & - & - & 0,15 & 6,87 & 0,14 & 5,79 & 0,16 & 7,24 \\
\hline Máximo & - & - & 0,84 & 96,44 & 0,85 & 96,67 & 0,85 & 96,66 \\
\hline Mínimo & - & - & 0,37 & 74,71 & 0,41 & 77,64 & 0,37 & 74,49 \\
\hline
\end{tabular}

${ }^{(1)}$ Todas as médias diferem entre si a $1 \%$ de probabilidade pelo teste $\mathrm{F}$. açúcar nos 16 experimentos, tendo em vista também os diferentes métodos empregados (Tabelas 2, 3 e 4), em geral, foram consistentes e altas, exceto para os tratamentos 9 e 12, com altas estimativas de coeficientes de variação (CV). Também observaram-se valores de pequena magnitude para estimativas de repetibilidade (r). Estes efeitos podem ocorrer em razão de diversos fatores, como os genótipos analisados nestes experimentos, o controle experimental, e variações ambientais como sazonalidade. As estimativas destes experimentos influenciaram o decréscimo da estimativa média de repetibilidade e coeficiente de determinação, e o acréscimo do número de medidas necessárias. Os resultados evidenciam que o grande número de experimentos analisados é mais confiável, por demonstrar variações entre experimentos, revelando consistência e confiabilidade nas estimativas de repetibilidade, tornando um valor médio mais preciso. Valores altos de repetibilidade são desejáveis, pois, de acordo com Cruz \& Regazzi (2001), espera-se que, ao escolher um genótipo, sua superioridade inicial perdure; e a veracidade desta expectativa é corroborada pelo coeficiente de repetibilidade, que, quanto mais alto, menor o número de medidas repetidas para predizer o valor real do indivíduo.

Tabela 4. Médias dos ensaios, coeficientes de variação experimental, estimativas de coeficientes de determinação e de repetibilidade, obtidos pelos métodos da análise de variância (ANOVA), método de componentes principais (CP) e método de análise estrutural (AE), da característica tonelada de pol (sacarose) no caldo de cana por hectare (TPH) de genótipos de cana-de-açúcar.

\begin{tabular}{|c|c|c|c|c|c|c|c|c|}
\hline \multirow[t]{2}{*}{ Experimento } & \multirow[t]{2}{*}{ Média $^{(1)}$} & \multirow{2}{*}{$\begin{array}{l}\mathrm{CV} \\
(\%)\end{array}$} & \multicolumn{2}{|c|}{ ANOVA } & \multicolumn{2}{|c|}{$\mathrm{CP}$} & \multicolumn{2}{|c|}{$\mathrm{AE}$} \\
\hline & & & $\mathrm{r}$ & $\mathrm{R}^{2}$ & $\mathrm{r}$ & $\mathrm{R}^{2}$ & $\mathrm{r}$ & $\mathrm{R}^{2}$ \\
\hline 1 & 15,48 & 11,11 & 0,81 & 95,46 & 0,83 & 96,17 & 0,83 & 96,09 \\
\hline 2 & 12,97 & 7,20 & 0,74 & 93,46 & 0,76 & 94,21 & 0,76 & 94,09 \\
\hline 3 & 13,02 & 9,27 & 0,77 & 94,43 & 0,79 & 94,98 & 0,79 & 94,93 \\
\hline 4 & 12,98 & 10,49 & 0,64 & 92,68 & 0,67 & 93,33 & 0,66 & 93,05 \\
\hline 5 & 11,92 & 11,73 & 0,63 & 89,32 & 0,64 & 90,06 & 0,58 & 87,53 \\
\hline 6 & 13,87 & 12,20 & 0,60 & 88,11 & 0,63 & 89,37 & 0,60 & 88,34 \\
\hline 7 & 11,42 & 11,47 & 0,69 & 91,84 & 0,73 & 93,23 & 0,73 & 93,13 \\
\hline 8 & 11,39 & 11,40 & 0,57 & 87,07 & 0,62 & 89,13 & 0,60 & 88,29 \\
\hline 9 & 12,45 & 17,60 & 0,32 & 70,35 & 0,48 & 82,37 & 0,32 & 70,55 \\
\hline 10 & 11,83 & 6,83 & 0,66 & 90,82 & 0,69 & 91,80 & 0,66 & 90,83 \\
\hline 11 & 13,77 & 8,14 & 0,74 & 93,57 & 0,76 & 94,14 & 0,76 & 94,02 \\
\hline 12 & 13,16 & 9,60 & 0,32 & 70,06 & 0,34 & 71,87 & 0,33 & 71,48 \\
\hline 13 & 15,96 & 8,18 & 0,60 & 90,18 & 0,61 & 90,51 & 0,60 & 89,93 \\
\hline 14 & 14,31 & 9,51 & 0,63 & 89,62 & 0,67 & 90,92 & 0,66 & 90,60 \\
\hline 15 & 16,35 & 11,79 & 0,66 & 90,74 & 0,69 & 91,71 & 0,67 & 90,94 \\
\hline 16 & 10,99 & 12,44 & 0,27 & 65,44 & 0,31 & 69,64 & 0,28 & 65,75 \\
\hline Média & - & - & 0,60 & 87,07 & 0,64 & 88,97 & 0,61 & 87,47 \\
\hline Desvio & - & - & 0,16 & 9,48 & 0,15 & 7,80 & 0,17 & 9,43 \\
\hline Máximo & - & - & 0,81 & 95,46 & 0,83 & 96,17 & 0,83 & 96,09 \\
\hline Mínimo & - & - & 0,27 & 65,44 & 0,31 & 69,64 & 0,28 & 65,75 \\
\hline
\end{tabular}

${ }^{(1)}$ Todas as médias diferem entre si a $1 \%$ de probabilidade pelo teste $\mathrm{F}$. 
Os métodos empregados proporcionaram estimativas bem semelhantes nas três características. A característica TCH apresentou as seguintes médias das estimativas de repetibilidade (r) e coeficiente de determinação $\left(\mathrm{R}^{2}\right)$ conforme os métodos de análises: ANOVA - r = 0,66 e $\mathrm{R}^{2}=90,20 \%$; $C P-r=0,68$ e $\mathrm{R}^{2}=91,40 \% ; \mathrm{AE}-\mathrm{r}=0,67$ e $\mathrm{R}^{2}=90,62 \%$ (Tabela 2). Em relação à característica PCC, os valores foram: ANOVA - $\mathrm{r}=0,62$ e $\mathrm{R}^{2}=88,17 \%$; $\mathrm{CP}-\mathrm{r}=0,64$ e $\mathrm{R}^{2}=89,27 \%$; AE $-\mathrm{r}=0,62$ e $\mathrm{R}^{2}=87,99 \%$ (Tabela 3), e à característica TPH, as médias das estimativas foram: ANOVA $-\mathrm{r}=0,60$ e $\mathrm{R}^{2}=87,07 \%$; $\mathrm{CP}-\mathrm{r}=0,64$ e $\mathrm{R}^{2}=88,97 \%$; $\mathrm{AE}-\mathrm{r}=0,61$ e $\mathrm{R}^{2}=87,47 \%$ (Tabela 4). Da mesma forma, Shimoya et al. (2002), trabalhando com genótipos de capim-elefante, não encontraram diferenças notórias em relação às estimativas de repetibilidade geradas pelos diferentes métodos citados anteriormente. Assim, manifesta-se a regularidade na expressão das características TCH, PCC e TPH neste estudo, podendo-se supor que enunciam bom controle genético.

Os coeficientes de determinação, que demonstram a confiabilidade do valor fenotípico em predizer o valor real dos genótipos, apresentaram valores médios superiores a $80 \%$ quanto às três características avaliadas. Estes valores de confiabilidade são referenciados como elevados, uma vez que, segundo Resende (2002), quando seleciona-se um grupo de indivíduos, valores acima de $80 \%$ já podem ser considerados adequados.

A variação encontrada quanto à repetibilidade, estimada pelos três métodos, para a característica PCC, foi de $0,37 \leq r \leq 0,84$, uma amplitude e limites, superior e inferior, maiores que os relatados por Miller \& James (1975), que observaram repetibilidade de $0,30 \leq r \leq 0,50$. Santos et al. (2004), trabalhando com cana-de-açúcar, ao utilizarem os métodos dos componentes principais e análise de variância, obtiveram estimativas de coeficientes de repetibilidade para TCH próximas às encontradas no presente trabalho. Com relação à característica PCC, estes mesmos autores encontraram estimativas em torno de 0,45 , inferiores às encontradas neste trabalho. Já quanto à característica TPH, obtiveram estimativas de 0,47 pela análise de variância e 0,49 por componentes principais, considerados valores pequenos em relação aos encontrados neste trabalho, que evidenciou melhor controle genético desta característica, ou minimização das influências ambientais nas condições experimentais deste trabalho.

As estimativas do número de medições necessárias para se obter valores de $80 \%, 90 \%$ e $95 \%$ de predição do valor real do indivíduo (ou coeficiente de determinação) demonstraram que, em todas as características, os valores obtidos pelas três metodologias foram próximos (Tabela 5). Em relação à característica TCH, estabelecendo-se valor de $\mathrm{R}^{2}$ igual a 0,80 , pode-se predizer que são necessárias duas medições para inferir com segurança a superioridade de um genótipo em relação a outro. Entretanto, se for estabelecido necessidade de maior confiabilidade, expressa por $\mathrm{R}^{2}$ igual a 0,90 , seriam necessárias cinco medições, ao passo que, ao estabelecer $\mathrm{R}^{2}$ igual a 0,95 , seriam necessárias dez medições, ou cortes, para praticar a seleção com a confiabilidade

Tabela 5. Número necessário de medições (cortes) para seleção genotípica, considerando diferentes coeficientes de determinação da característica toneladas de colmo por hectare (TCH), avaliada em genótipos de cana-de-açúcar, a partir da repetibilidade estimada pelos métodos da análise de variância (ANOVA), método de componentes principais (CP) e método de análise estrutural (AE).

\begin{tabular}{|c|c|c|c|c|c|c|c|c|c|}
\hline \multirow[t]{2}{*}{ Experimentos } & \multicolumn{3}{|c|}{ ANOVA } & \multicolumn{3}{|c|}{$\mathrm{CP}$} & \multicolumn{3}{|c|}{$\mathrm{AE}$} \\
\hline & $\mathrm{R}^{2}=0,8$ & $\mathrm{R}^{2}=0,9$ & $\mathrm{R}^{2}=0,95$ & $\mathrm{R}^{2}=0,8$ & $\mathrm{R}^{2}=0,9$ & $\mathrm{R}^{2}=0,95$ & $\mathrm{R}^{2}=0,8$ & $\mathrm{R}^{2}=0,9$ & $\mathrm{R}^{2}=0,95$ \\
\hline 1 & 0,87 & 1,95 & 4,12 & 0,80 & 1,80 & 3,80 & 0,82 & 1,85 & 3,90 \\
\hline 2 & 2,01 & 4,52 & 9,54 & 1,82 & 4,10 & 8,65 & 1,89 & 4,26 & 9,00 \\
\hline 3 & 1,88 & 4,23 & 8,93 & 1,73 & 3,89 & 8,21 & 1,80 & 4,06 & 8,57 \\
\hline 4 & 2,05 & 4,60 & 9,72 & 1,85 & 4,17 & 8,80 & 1,91 & 4,43 & 9,06 \\
\hline 5 & 2,09 & 4,69 & 9,90 & 1,92 & 4,32 & 9,11 & 2,15 & 4,83 & 10,20 \\
\hline 6 & 2,07 & 4,66 & 9,83 & 1,84 & 4,15 & 8,76 & 1,95 & 4,40 & 9,28 \\
\hline 7 & 1,85 & 4,16 & 8,77 & 1,56 & 3,51 & 7,40 & 1,58 & 3,55 & 7,50 \\
\hline 8 & 2,51 & 5,65 & 11,93 & 2,11 & 4,75 & 10,04 & 2,22 & 4,99 & 10,53 \\
\hline 9 & 5,52 & 12,42 & 26,23 & 3,40 & 7,65 & 16,14 & 5,54 & 12,46 & 26,30 \\
\hline 10 & 1,50 & 3,38 & 7,14 & 1,29 & 2,91 & 6,15 & 1,42 & 3,19 & 6,74 \\
\hline 11 & 0,86 & 1,94 & 4,10 & 0,76 & 1,72 & 3,63 & 0,77 & 1,73 & 3,65 \\
\hline 12 & 4,15 & 9,34 & 19,71 & 3,72 & 8,36 & 17,65 & 3,89 & 8,74 & 18,46 \\
\hline 13 & 2,69 & 6,06 & 12,79 & 2,58 & 5,81 & 12,27 & 2,67 & 6,02 & 12,71 \\
\hline 14 & 1,20 & 2,69 & 5,68 & 1,07 & 2,41 & 5,09 & 1,10 & 2,47 & 5,22 \\
\hline 15 & 1,69 & 3,81 & 8,04 & 1,51 & 3,40 & 7,19 & 1,62 & 3,64 & 7,68 \\
\hline 16 & 3,86 & 8,69 & 18,34 & 3,67 & 8,26 & 17,44 & 3,82 & 8,60 & 18,15 \\
\hline Média & 2,30 & 5,17 & 10,92 & 1,98 & 4,45 & 9,40 & 2,20 & 4,95 & 10,43 \\
\hline Desvio & 1,25 & 2,81 & 5,93 & 0,93 & 2,09 & 4,42 & 1,26 & 2,83 & 5,97 \\
\hline Máximo & 5,52 & 12,42 & 26,23 & 3,72 & 8,36 & 17,65 & 5,54 & 12,46 & 26,30 \\
\hline Mínimo & 0,86 & 1,94 & 4,10 & 0,76 & 1,72 & 3,63 & 0,77 & 1,73 & 3,65 \\
\hline
\end{tabular}


desejada. Quanto à característica PCC, ao número de medições necessárias para se ter $\mathrm{R}^{2}$ igual a 0,80 no processo de seleção dos genótipos, é necessário realizar três medições, ao passo que para $\mathrm{R}^{2}$ igual a 0,90 ou 0,95 , são necessários 6 e 13 cortes, respectivamente (Tabela 6). Com relação à característica TPH, o número de medições necessárias para $\mathrm{R}^{2}$ igual a 0,80 é três. Para maiores confiabilidades, em que o $\mathrm{R}^{2}$ seja igual a 0,90 ou 0,95, são necessárias 7 ou 15 medições (cortes), respectivamente (Tabela 7).
Assim, nos programas de melhoramento de cana-deaçúcar, quanto às três características avaliadas, podese dizer que três medições possibilitariam discriminação dos genótipos com $80 \%$ de probabilidade de se estar fundamentado no valor real de cada um deles. Tal nível de confiabilidade tem sido considerado adequado em esquemas seletivos (Resende, 2002). Indicação semelhante para a característica TCH foi constatada por Santos et al. (2004). Estes mesmos autores encontraram para as características PCC e TPH, com três medições, $\mathrm{R}^{2}<0,80$.

Tabela 6. Número necessário de medições (cortes) para seleção genotípica, considerando diferentes coeficientes de determinação da característica teor de sacarose dos colmos (pol porcento cana - PCC) avaliada em genótipos de cana-de-açúcar, a partir da repetibilidade estimada pelos métodos da análise de variância (ANOVA), método de componentes principais (CP) e método de análise estrutural (AE).

\begin{tabular}{|c|c|c|c|c|c|c|c|c|c|}
\hline \multirow[t]{2}{*}{ Experimentos } & \multicolumn{3}{|c|}{ ANOVA } & \multicolumn{3}{|c|}{$\mathrm{CP}$} & \multicolumn{3}{|c|}{$\mathrm{AE}$} \\
\hline & $\mathrm{R}^{2}=0,8$ & $\mathrm{R}^{2}=0,9$ & $\mathrm{R}^{2}=0,95$ & $\mathrm{R}^{2}=0,8$ & $\mathrm{R}^{2}=0,9$ & $\mathrm{R}^{2}=0,95$ & $\mathrm{R}^{2}=0,8$ & $\mathrm{R}^{2}=0,9$ & $\mathrm{R}^{2}=0,95$ \\
\hline 1 & 4,25 & 9,55 & 20,17 & 4,06 & 9,14 & 19,29 & 4,30 & 9,68 & 20,44 \\
\hline 2 & 1,05 & 2,35 & 4,96 & 0,98 & 2,20 & 4,64 & 0,99 & 2,22 & 4,68 \\
\hline 3 & 0,74 & 1,66 & 3,51 & 0,69 & 1,55 & 3,27 & 0,69 & 1,56 & 3,28 \\
\hline 4 & 2,54 & 5,70 & 12,04 & 2,42 & 5,44 & 11,49 & 2,45 & 5,52 & 11,66 \\
\hline 5 & 1,79 & 4,03 & 8,52 & 1,65 & 3,72 & 7,86 & 1,70 & 3,81 & 8,05 \\
\hline 6 & 1,22 & 2,75 & 5,81 & 1,18 & 2,65 & 5,58 & 1,19 & 2,67 & 5,63 \\
\hline 7 & 1,43 & 3,22 & 6,80 & 1,39 & 3,12 & 6,58 & 1,42 & 3,19 & 6,74 \\
\hline 8 & 2,82 & 6,35 & 13,41 & 2,80 & 6,30 & 13,29 & 2,91 & 6,55 & 13,83 \\
\hline 9 & 4,76 & 10,71 & 22,60 & 3,78 & 8,49 & 17,93 & 5,15 & 11,58 & 24,44 \\
\hline 10 & 5,99 & 13,48 & 28,47 & 4,45 & 10,02 & 21,15 & 6,85 & 15,41 & 32,54 \\
\hline 11 & 0,79 & 1,77 & 3,73 & 0,72 & 1,63 & 3,43 & 0,73 & 1,64 & 3,46 \\
\hline 12 & 6,77 & 15,23 & 32,16 & 5,76 & 12,96 & 27,37 & 6,47 & 14,57 & 30,75 \\
\hline 13 & 2,37 & 5,34 & 11,26 & 2,15 & 4,84 & 10,22 & 2,17 & 4,87 & 10,28 \\
\hline 14 & 2,94 & 6,62 & 13,98 & 2,79 & 6,28 & 13,25 & 2,89 & 6,49 & 13,71 \\
\hline 15 & 4,30 & 9,68 & 20,44 & 3,85 & 8,66 & 18,28 & 4,18 & 9,40 & 19,84 \\
\hline 16 & 2,46 & 5,54 & 11,69 & 2,32 & 5,23 & 11,04 & 3,19 & 7,17 & 15,14 \\
\hline Média & 2,89 & 6,50 & 13,72 & 2,56 & 5,76 & 12,17 & 2,95 & 6,65 & 14,03 \\
\hline Desvio & 1,85 & 4,16 & 8,77 & 1,48 & 3,34 & 7,05 & 1,96 & 4,41 & 9,31 \\
\hline Máximo & 6,77 & 15,23 & 32,16 & 5,76 & 12,96 & 27,37 & 6,85 & 15,41 & 32,54 \\
\hline Mínimo & 0,74 & 1,66 & 3,51 & 0,69 & 1,55 & 3,27 & 0,69 & 1,56 & 3,28 \\
\hline
\end{tabular}

Tabela 7. Número necessário de medições (cortes) para seleção genotípica, considerando diferentes coeficientes de determinação da característica tonelada de pol (sacarose) no caldo da cana por hectare (TPH) avaliada em genótipos de cana-de-açúcar, a partir da repetibilidade estimada pelos métodos da análise de variância (ANOVA), método de componentes principais (CP) e método de análise estrutural (AE).

\begin{tabular}{|c|c|c|c|c|c|c|c|c|c|}
\hline \multirow[t]{2}{*}{ Experimentos } & \multicolumn{3}{|c|}{ ANOVA } & \multicolumn{3}{|c|}{$\mathrm{CP}$} & \multicolumn{3}{|c|}{$\mathrm{AE}$} \\
\hline & $\mathrm{R}^{2}=0,8$ & $\mathrm{R}^{2}=0,9$ & $\mathrm{R}^{2}=0,95$ & $\mathrm{R}^{2}=0,8$ & $\mathrm{R}^{2}=0,9$ & $\mathrm{R}^{2}=0,95$ & $\mathrm{R}^{2}=0,8$ & $\mathrm{R}^{2}=0,9$ & $\mathrm{R}^{2}=0,95$ \\
\hline 1 & 0,95 & 2,14 & 4,52 & 0,80 & 1,79 & 3,79 & 0,81 & 1,83 & 3,86 \\
\hline 2 & 1,40 & 3,15 & 6,65 & 1,23 & 2,77 & 5,84 & 1,26 & 2,83 & 5,97 \\
\hline 3 & 1,18 & 2,65 & 5,60 & 1,06 & 2,38 & 5,02 & 1,07 & 2,40 & 5,07 \\
\hline 4 & 2,21 & 4,98 & 10,51 & 2,00 & 4,50 & 9,51 & 2,09 & 4,70 & 9,93 \\
\hline 5 & 2,39 & 5,38 & 11,36 & 2,21 & 4,97 & 10,49 & 2,85 & 6,41 & 13,54 \\
\hline 6 & 2,70 & 6,08 & 12,83 & 2,38 & 5,36 & 11,31 & 2,64 & 5,94 & 12,54 \\
\hline 7 & 1,78 & 4,00 & 8,44 & 1,45 & 3,27 & 6,90 & 1,48 & 3,32 & 7,01 \\
\hline 8 & 2,97 & 6,69 & 14,11 & 2,44 & 5,49 & 11,58 & 2,65 & 5,97 & 12,60 \\
\hline 9 & 8,43 & 18,97 & 40,04 & 4,28 & 9,06 & 20,33 & 8,35 & 18,78 & 39,65 \\
\hline 10 & 2,02 & 4,55 & 9,61 & 1,79 & 4,02 & 8,48 & 2,02 & 4,54 & 9,59 \\
\hline 11 & 1,38 & 3,10 & 6,53 & 1,25 & 2,80 & 5,92 & 1,27 & 2,86 & 6,04 \\
\hline 12 & 8,55 & 19,23 & 40,60 & 7,83 & 17,62 & 37,19 & 7,98 & 17,96 & 37,91 \\
\hline 13 & 2,61 & 5,88 & 12,41 & 2,52 & 5,66 & 11,95 & 2,69 & 6,05 & 12,76 \\
\hline 14 & 2,32 & 5,21 & 11,01 & 2,00 & 4,49 & 9,49 & 2,08 & 4,67 & 9,85 \\
\hline 15 & 2,04 & 4,59 & 9,69 & 1,81 & 4,07 & 8,59 & 1,99 & 4,48 & 9,46 \\
\hline 16 & 10,56 & 23,76 & 50,16 & 8,72 & 19,62 & 41,43 & 10,42 & 23,44 & 49,48 \\
\hline Média & 3,34 & 7,52 & 15,88 & 2,73 & 6,12 & 12,99 & 3,23 & 7,26 & 15,33 \\
\hline Desvio & 2,98 & 6,71 & 14,16 & 2,31 & 5,18 & 10,99 & 2,93 & 6,59 & 13,90 \\
\hline Máximo & 10,56 & 23,76 & 50,16 & 8,72 & 19,62 & 41,43 & 10,42 & 23,44 & 49,48 \\
\hline Mínimo & 0,95 & 2,14 & 4,52 & 0,80 & 1,79 & 3,79 & 0,81 & 1,83 & 3,86 \\
\hline
\end{tabular}


No programa de melhoramento genético de cana-deaçúcar da RIDESA realizam-se, no mínimo, três cortes na fase final de avaliação dos clones promissores nas terras das usinas e destilarias. A aplicação do menor número de medições é desejável, em termos de economia de tempo e mão-de-obra. Assim, a utilização de um número maior de colheitas não é vantajoso, tendo em vista aspectos práticos e econômicos. Três medições parecem ser adequadas tanto para aplicação técnica e prática quanto para que o sucesso de um programa de melhoramento genético não seja comprometido.

\section{Conclusões}

1. As estimativas dos coeficientes de repetibilidade obtidas pelos métodos de ANOVA, CP e AE apresentam valores de magnitude muito semelhantes.

2. As estimativas de repetibilidade média geral, nas três características, é superior a 0,60, demonstrando regularidade do desempenho dos genótipos nas várias medições (cortes) e confiabilidade na discriminação genotípica superior a $87 \%$.

3. Os métodos de ANOVA, CP e AE evidenciam, quanto às características TCH, TPH e PCC, que o emprego de três cortes é adequado para que a seleção em programa de melhoramento possa ser praticada com previsibilidade do valor real do genótipo acima de $80 \%$.

\section{Referências}

ABEYWARDENA, V. An application of principal component analysis in genetics. Journal of Genetics, v.16, p.27-51, 1972.

BARBOSA, G.V.S.; SOUZA, A.J.R.; ROCHA, A.M.C.; RIBEIRO, C.A.G.; FERREIRA, J.L.C.; SOARES, L.; CRUZ, M.M.; SILVA, W.C.M. Novas variedades RB de cana-de-açúcar para Alagoas. Maceió: UFAL; Programa de Melhoramento Genético de Cana-deAçúcar, 2000. 16p. (Boletim Técnico Programa de Melhoramento Genético de Cana-de-Açúcar, 1).

BOTREL, M.A.; FERREIRA, R.P.; CRUZ, C.D.; PEREIRA, A.V.; VIANA, M.C.M.; ROCHA, R.; MIRANDA, M. Estimativas de coeficientes de repetibilidade para produção de matéria seca em cultivar de alfafa, sob diferentes ambientes. Revista Ceres, v.47, p.651-663, 2000.

CRUZ, C.D. Programa GENES: aplicativo computacional em genética e estatística. Viçosa, MG: UFV, 1997. 442p.

CRUZ, C.D.; REGAZZI, A.J. Modelos biométricos aplicados ao melhoramento genético. 2.ed. rev. Viçosa, MG: UFV, 2001. 390p.

CUENYA, M.I.; MARIOTTI, J.A. Repetibilidad de la expresion en etapas tempranas de seleccion en progenies hibridas de caña de azucar (Saccharum spp.). Revista Industrial y Agrícola de Tucumán, v.70, p.41-48, 1993.

FALCONER, D.S.; MACKAY, T.F.C. Hereditability and repeatability discussion: sugarcane breeders'. International Society of Sugar Cane Technology, v.18, p.15-17, 1966.

FERREIRA, R.P.; BOTREL, M.A.; PEREIRA, A.V.; CRUZ, C.D. Avaliação de cultivares de alfafa e estimativas de repetibilidade de caracteres forrageiros. Pesquisa Agropecuária Brasileira, v.34, p.995-1002, 1999.

MANSOUR, H.; NORDHEIM, E.V.; RULEDGE, J.J. Estimators of repeatability. Theoretical and Applied Genetics, v.60, p.151156, 1981.

MARIOTTI, J.A. Experiencias de seleccion clonal em cana de azúcar en la provincia de Jujuy: repetibilidad y heredabilidad de caracteres de interesse agronómico. Revista Agronómica Norte Argentina, v.10, p.61-73, 1973.

MILLER, J.D.; JAMES, N.I. Selection in six crops of sugarcane. IRepeatability of three characters. Crop Science, v.15, p.23-25, 1975.

RESENDE, M.D.V. de. Genética biométrica e estatística no melhoramento de plantas perenes. Brasília: Embrapa Informação Tecnológica, 2002.975p.

ROSSE, L.N.; VENCOVSKY, R.; FERREIRA, A. Comparação de métodos de regressão para avaliar a estabilidade fenotípica em canade-açúcar. Pesquisa Agropecuária Brasileira, v.37, p.25-32, 2002.

RUTLEDGE, J.J. A scaling which remove bias of Abeywardena's estimator of repeatability. Journal of Genetics, v.61, p.247-250, 1974.

SANTOS, M.S.M. dos; MADALENA, J.A.; SOARES, L.; FERREIRA, P.V.; BARBOSA, G.V.S. Repetibilidade de características agroindustriais em cana-de-açúcar. Pesquisa Agropecuária Brasileira, v.39, p.301-306, 2004

SHIMOYA, A.; PEREIRA, A.V.; FERREIRA, R. de P.; CRUZ, C.D.; CARNEIRO, P.C.S. Repetibilidade de características forrageiras do capim-elefante. Scientia Agricola, v.59, p.227-234, 2002.

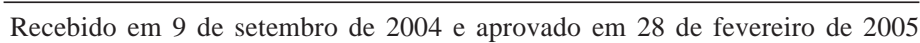

